\section{Should the MTHFR 1298A>C polymorphism be considered in the clinical evaluation of patients at risk for thrombotic disease?}

\section{To the Editor:}

I read with great interest the study by Brown et al. on the detection of methylenetetrahydrofolate reductase (MTHFR) 677T/1298C (double variant) haplotypes among patients undergoing thrombophilia evaluation. ${ }^{1}$ Brown et al. state that individuals with the compound heterozygous 677CT/1298AC genotype, i.e., with the variant alleles in trans, are at increased risk for thrombotic disease, and that the most important implication of their 677T/1298C haplotype discovery is that linkage analysis may be required to make a valid risk assessment in individuals with 677CT/1298AC genotypes. Their argument may however, be misleading since their first statement does not seem correct. There are to my knowledge no studies supporting an association between the compound heterozygous 677CT/1298AC genotype and thrombotic disease as yet. ${ }^{2-5}$

The association between hyperhomocysteinema and arterial or venous thrombosis is not controversial and many studies have shown that the hyperhomocysteinemia-associated MTHFR 677TT genotype seems to be a risk factor for thrombotic disease.6,7 The biological implications of inheriting one or two 1298C alleles are however, much more elusive. A PubMed search in June 2005 reveals that only one study has verified an association between elevated homocysteine concentration and the $1298 \mathrm{C}$ allele. ${ }^{8}$ Only three studies report an association between the compound heterozygous MTHFR 677CT/1298AC genotype and elevated homocysteine, ${ }^{9-11}$ while there are more than 25 negative studies of reasonable size. The importance of the $1298 \mathrm{~A}>\mathrm{C}$ polymorphism has also been questioned from a biochemical point of view. ${ }^{12}$ Compatible with the negative studies, Yamada et al. found that purified 1298C-encoded MTHFR showed no difference from wild type either in its kinetic or stabilizing properties regardless if in cis with $677 \mathrm{C}$ or $677 \mathrm{~T} .{ }^{12}$ In conclusion, one may question if the MTHFR 1298A $>$ C genotype should be considered at all at this stage in the clinical evaluation of patients at risk for thrombotic disease outside the research setting.

Henrik Zetterberg, $\mathrm{MD}, \mathrm{PhD}$ Sahlgrenska University Hospital Göteborg University Sweden; Brigham and Women's Hospital and Harvard Medical School Boston, Massachusetts
3. Friso S, Girelli D, Trabetti E, Stranieri C, et al. A1298C methylenetetrahydrofolate reductase mutation and coronary artery disease: relationships with C677T polymorphism and homocysteine/folate metabolism. Clin Exp Med 2002;2:7-12.

4. Hanson NQ, Aras O, Yang F, Tsai MY. C677T and A1298C polymorphisms of the methylenetetrahydrofolate reductase gene: incidence and effect of combined genotypes on plasma fasting and post-methionine load homocysteine in vascular disease. Clin Chem 2001;47:661-666.

5. Meisel C, Cascorbi I, Gerloff T, Stangl V, et al. Identification of six methylenetetrahydrofolate reductase (MTHFR) genotypes resulting from common polymorphisms: impact on plasma homocysteine levels and development of coronary artery disease. Atherosclerosis 2001;154:651-658.

6. Den Heijer M, Lewington S, Clarke R. Homocysteine, MTHFR and risk of venous thrombosis: a meta-analysis of published epidemiological studies. J Thromb Haemost 2005;3:292-299.

7. Kim RJ, Becker RC. Association between factor V Leiden, prothrombin G20210A, and methylenetetrahydrofolate reductase C677T mutations and events of the arterial circulatory system: a meta-analysis of published studies. Am Heart J 2003;146: 948-957.

8. Haviv YS, Shpichinetsky V, Goldschmidt N, Atta IA, Ben-Yehuda A, Friedman G. The common mutations C677T and A1298C in the human methylenetetrahydrofolate reductase gene are associated with hyperhomocysteinemia and cardiovascular disease in hemodialysis patients. Nephron 2002;92:120-126.

9. Lachmeijer AM, Arngrimsson R, Bastiaans EJ, Pals G, et al. Mutations in the gene for methylenetetrahydrofolate reductase, homocysteine levels, and vitamin status in women with a history of preeclampsia. Am J Obstet Gynecol 2001;184:394-402.

10. van der Put NM, Gabreels F, Stevens EM, Smeitink JA, et al. A second common mutation in the methylenetetrahydrofolate reductase gene: an additional risk factor for neural-tube defects? Am J Hum Genet 1998;62:1044-1051.

11. Weisberg IS, Jacques PF, Selhub J, Bostom AG, et al. The 1298A->C polymorphism in methylenetetrahydrofolate reductase (MTHFR): in vitro expression and association with homocysteine. Atherosclerosis 2001;156:409-415.

12. Yamada K, Chen Z, Rozen R, Matthews RG. Effects of common polymorphisms on the properties of recombinant human methylenetetrahydrofolate reductase. Proc Natl Acad Sci U S A 2001;98:14853-14858.

\title{
References
}

1. Brown NM, Pratt VM, Buller A, Pike-Buchanan L, et al. Detection of 677CT/ 1298AC "double variant" chromosomes: implications for interpretation of MTHFR genotyping results. Genet Med 2005;7:278-282.

2. Domagala TB, Adamek L, Nizankowska E, Sanak M, Szczeklik A. Mutations C677T and A1298C of the 5,10-methylenetetrahydrofolate reductase gene and fasting plasma homocysteine levels are not associated with the increased risk of venous thromboembolic disease. Blood Coagul Fibrinolysis 2002;13:423-431. 